\title{
Risk Control Technology Combining Production and Finance in the Process of New and Old Kinetic Energy Conversion
}

\author{
Liu Jilu $^{1}$, Wang Chunfang ${ }^{2 *}$ and Tan Weibing ${ }^{3}$ \\ ${ }^{1}$ Weifang Vocational College (Weifang, Shandong, China: 262737) \\ ${ }^{2}$ Weifang Vocational College (Weifang, Shandong, China: 262737) \\ ${ }^{3}$ Weifang Vocational College (Weifang, Shandong, China: 262737) \\ Corresponding author's address: Wang Chunfang, No. 06588, Hai'an Road, Science and Education Innovation Park, \\ Binhai Economic and Technological Development Zol ne, Weifang City, Shandong Province Post Code: 262737 Email: \\ sdwfwcf@126.com, Tel 13563682513
}

\begin{abstract}
At present, our country is in a period of transition of new and old economic energies and social transformation. Neither the strategic structural adjustment of the industrial field nor the deepening reform of the financial industry has been finalized. Under such circumstances and conditions, the development path that combines production and finance will undoubtedly contain more risk factors. Under the situation that largescale enterprise groups lead the combination of production and finance, managers must effectively balance the development relationship between the original leading industry and the newly added financial business. The purpose of doing so is to avoid that companies chase short-term financial industry profits and accumulate and amplify their business risks, so that industrial capital directs or kidnaps financial capital. The risk control of the combination of production and finance has become an important issue that needs to be addressed in the industrial field and the entire national economic system.
\end{abstract}

Keywords: equity conversion of old and new kinetic energy, combination of production and finance, risk control

\section{INTRODUCTION}

In the current situation, accelerating the conversion of old and new kinetic energy is the only way to actively adapt to the new normal of economic development and further advance supply-side structural reforms. Managers should explore new models and new paths for production and financial cooperation, and actively cultivate new advantages and new financial momentum for the combination of production and finance. These measures can guide social capital into the real economy, which is closely related to the development of the country. It can realize the efficient allocation of resources, promote the quality and efficiency of the real economy, and promote the conversion of new and old kinetic energy.But managers should be more soberly aware that while the combination of production and finance brings many benefits, it also has many potential risks. In order to strengthen the anti-risk ability of industrial enterprises and prevent the formation of a new economic bubble, managers should strengthen the analysis, evaluation, control and resolution of risks associated with production and finance. These measures can promote the conversion of new and old kinetic energy into the fast track of healthy development.

\section{CONNOTATION OF NEW AND OLD KINETIC ENERGY CONVERSION}

The connotation of the conversion of new and old kinetic energy is: the new model replaces the old model, the new format replaces the old format, new technology replaces old technology, new materials replace old materials, and new energy replaces old energy. The conversion of old and new kinetic energy can realize industrial upgrading and change in the mode of economic growth. The mode of economic growth has changed from quantitative growth to qualitative growth, extended growth to connotative growth, or laborintensive to knowledge-intensive economic growth. The essence of the conversion of new and old kinetic energy is the transformation of economic growth methods. The core is the transformation of the core driving mechanism of industrial upgrading, that is, the transformation from the price mechanism to the value mechanism, the reduction from transaction costs to the increase in added value, and the improvement from marginal efficiency to marginal efficiency Conversion, economic scale to scale economy, factor endowment comparative advantage to mass entrepreneurship, follow-up mode to modern economic system, from GDP economy to happiness economy. ${ }^{[1]}$

In the process of converting old and new kinetic energy, the combination of production and finance brings more than just positive effects. Behind the rapid accumulation and 
expansion of two different types of capital, industry and finance, there are also huge risks. These risks mainly include the problems brought by the backward and overcapacity industries to the combination of production and finance, the excessive investment in the financial industry caused by enterprises to derealize the risks, and the transfer of industrial and financial risks. These risks will not only lead to the failure of a single enterprise, but may also cause a shock or crisis in the entire economic system, which will affect the realization of the old and new kinetic energy conversion goals. Therefore, managers should conduct more in-depth thinking and research on the risks caused by the combination of production and finance at the current stage and their management and control issues..

\section{RISK FACTORS FOR THE COMBINATION OF PRODUCTION AND FINANCE DURING THE CONVERSION OF NEW AND OLD KINETIC ENERGY}

\subsection{Insufficient understanding of various risks in the combination of production and finance during the conversion of new and old kinetic energy}

In the process of the conversion of old and new kinetic energy, the strategic structural adjustment in the industrial field and the deepening reform of the financial industry have not been finally completed. The development of the combination of production and finance contains many risk factors, such as The damage to the leading industry value chain, the transmission of systemic risks within the financial industry, and the existence of intra-group trading risks. In the current situation, more and more industrial groups will inevitably choose the road of combined development of production and finance, balance the development relationship between the newly added financial business and the original leading industry, and avoid chasing excess profits in the short-term financial industry. And accumulating and amplifying the business risks of enterprises has become an important issue that the entire economy and society need to focus on. At the same time, the investment and financing and merger and acquisition business that frequently occurs during the combined development of production and finance is also a place where risks are gathered. For example, the complexity of the capital chain such as investment, borrowing and guarantees between the subsidiary and the parent company causes risks within the group Wide delivery etc. In addition, if we only focus on short-term high profits in the financial field and ignore the various risks that originally existed in the financial field, especially when the cooperation between enterprises with less clear property rights and under-standard financial operations will magnify the original potential Risk, and even end up in an uncontrollable state. For example, various operations with the cover of intricate internal related transactions and the purpose of "circling money" will inevitably lead to the accumulation of risks and ultimately the bankruptcy of the entire enterprise. ${ }^{[2]}$

\subsection{It is difficult to effectively integrate industrial capital and financial capital in the process of new and old kinetic energy conversion}

If an enterprise group implements the combination of production and finance, it must find the position of industry and finance in the development strategy of the enterprise. To achieve synergy in operations, only effective integration between industry and finance can be created for the enterprise group. More value. However, China is still in the initial stage of the combined development of production and finance, especially when industrial groups enter the financial field with low degree of correlation, effective integration of the two is often difficult to achieve in the short term; The focus is often on the short-term profit needs of the financial business field. It is not an effective operation and development mechanism that forms the integrated growth of industry and finance. It does not truly reflect the production of "permeability", "complementarity" and "combination optimization". The most basic characteristics that should be combined with finance. In general, due to the combination of production and finance in the conversion of old and new kinetic energy, due to the existence of "shortsightedness" and extensive involvement in "non-relevant financial business", there is still a lot of true integration and synergy between industrial capital and financial capital. Uncertainties and certain risks.

\subsection{The supervision system on the integration of production and finance in the process of new and old kinetic energy needs to be improved}

At this stage, China's financial supervision adopts the "one committee, one committee, two meetings" supervision model, and the combination of production and finance in the process of the conversion of new and old kinetic energy has various forms. The separate supervision and separate supervision of the financial supervisory authority have no effect on the combination of production and finance. Specialized and clear regulatory schemes. The current combination of production and finance is mainly from production to financing. Industrial groups directly control (participate in) financial companies, financial holding companies, mixed development, etc., and the channels for financial supervision departments to play a supervisory role are not smooth. Even financial companies with financial licenses that are more integrated with industrial capital, due to the complexity of the situation, the supervision of the bancassurance supervision department is also very difficult. In addition, the party that combines production and finance with the middle class also has different affiliation issues such as state-owned enterprises and private enterprises, central enterprises and land-based enterprises. With the 
At this stage, the risks in the development of domestic production and financial integration are complex and diverse. The impact of risk outbreaks is large. On the one hand, it may lead to the collapse of the enterprise itself, and on the other hand, it will also bring many negative effects to social and economic life. Therefore, it is a very important issue to prevent the risk of combining production with finance. It is recommended to implement comprehensive risk management from the inside to the outside, as shown in Figure1:

\section{THE MANAGEMENT AND CONTROL TECHNOLOGY OF THE MAIN RISKS OF THE COMBINATION OF PRODUCTION AND FINANCE DURING THE CONVERSION OF NEW AND OLD KINETIC ENERGY}

versification of industry management departments, the the supervision of the combination of production and inc Challenges. ${ }^{[3]}$

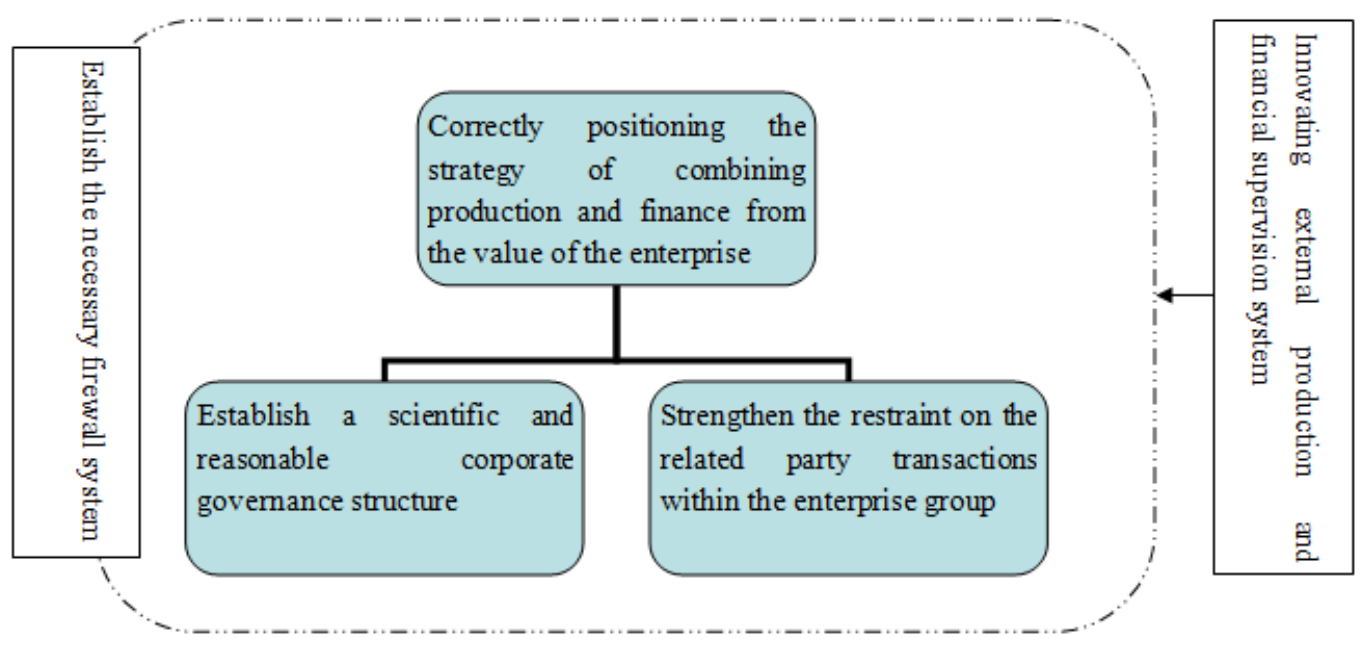

Figure 1. Portfolio of key risk management technologies that combine production and finance

\subsection{Correctly positioning the strategy of combining production and finance from the value of the enterprise}

Judging from the current realistic path of the domestic enterprise's production and financial integration and development of "integration from production to production", to develop a rational production and financial integration development strategy, the first requirement is that the enterprise should already be at a certain height, The steady rise of the industrial foundation can clearly recognize the prospect of the combined development of production and finance. Based on the principle of "main service industry", we cannot rely on financial services to support the industry, and the situation of "bottom and end" appears. Second, companies must fully study the stateowned construction. Macro policies on the combination of production and finance, combined with the development trend of the industry and national policy guidance, formulate a combination of production and finance strategy, and try to avoid related risks caused by policy adjustments. Third, companies must control their own financial capital, financial Make a comprehensive assessment of professional talent reserves and financial risk tolerance to make the right strategic choices.

\subsection{Establish a scientific and reasonable corporate governance structure}

At present, the development of China's capital market is not sufficient. To improve the efficiency of the combined development of production and finance, and to avoid risks in the combined development of production and finance, it is necessary to establish a scientific and reasonable corporate governance structure. A scientific and reasonable corporate governance structure can fully realize the power balance mechanism of shareholders, the board of directors, management and other stakeholders, and effectively improve the company's ability to resist risks. Strictly speaking, the corporate governance structure is a system framework that links and regulates the distribution of rights and obligations of shareholders, the board of directors, and senior management, as well as issues related to recruitment and supervision. When a productionfinance-integrated company establishes a corporate governance structure, it is necessary to clearly define the responsibilities and powers of the board of directors, 
management, supervisory board, and functional departments, and ensure that each institution performs its own duties and responsibilities. It is recommended to highlight the strategic position of the wind management department, establish a risk management committee in the supervisory board, and supervise the entire process of the integration of production and finance, including the approval, coordination and supervision of risk projects; meanwhile, in the business departments and transaction areas that may generate risks In addition, an independent risk management function is set up to be responsible for the daily risk management in the process of integrating production and finance, to manage, guide and report on enterprise risk management throughout the process, to improve the overall risk management level of the production and finance combined enterprise and to resist risks. ability. ${ }^{[4]}$

\subsection{Strengthen the restraint on the related party transactions within the enterprise group}

Production and finance combined enterprises can formulate strict rules and regulations, requiring all transactions between the parent and subsidiary companies of the group and each subsidiary must follow the principles of market transactions, that is, the transaction conditions between internal companies and the transaction conditions between non-affiliated companies Same; at the same time, real-time monitoring of major related transactions between internal companies, and restrictions on the number and size. For example, strict examination and approval of "relationship loans" and credit extensions of related subsidiaries by financial institutions controlled by production and finance combined enterprise groups.

\subsection{Establish the necessary firewall system}

An enterprise's firewall system is a system that prevents the mutual transmission of risks. A combination of production and finance mainly restricts the organization structure, business management, senior management, etc., and sets up barriers between parent and subsidiary companies and each subsidiary to block risks. To prevent the accumulation of risk. An enterprise group combining production and finance can set up equity, business, and personnel barriers between the group company and the financial subsidiary based on the equity relationship, operating model, and business characteristics of each member company to achieve relatively independent operation of industrial capital and financial capital. Prevent the chain reaction caused by the linkage of financial risk and industrial risk.

\subsection{Innovating external production and financial supervision system}

At present, China's industrial capital dominates the combination of production and finance. The scale of enterprise groups combined with production and finance is large, covering a wide range of industries and fields. When risks, especially industrial risks, are transmitted to financial risks, they are harmful and fast. In view of the current lack of relevant laws and regulations to supervise the combination of production and finance, the first is to suggest that the "one party and two associations" financial supervisory department should strengthen communication with industry authorities, pay close attention to risk points in the process of integrating production and finance, and urge the establishment of industrial and financial capital Firewall, trying to resolve financial risks in the bud. Secondly, it is recommended to clarify the management department of the financial business of a production and finance combination enterprise group, and to recommend the establishment of a production and finance integration industry association to give full play to the role of industry self-regulation, strengthen business industry management and business guidance, and promote the healthy development of production and finance integration. Strive to prevent and resolve financial risks during development. The third is to establish a coordinated supervision mechanism, reasonably divide the supervision scope and authority of the financial supervision department and the industrial supervision department, and establish an effective information sharing mechanism between crosssector supervision authorities to ensure the timely and effective transmission, communication and disclosure of information, so that the supervision institution can obtain Comprehensive, truthful, and complete information prevents systemic risks from occurring and effectively safeguards and protects the legitimate rights and interests of stakeholders.

\section{CONCLUSION}

$\mathrm{T}$ Through the previous analysis, it can be found that the risk factors of the integration of industry and finance in the process of the conversion of new and old kinetic energy mainly include: insufficient understanding of various risks in the integration of industry and finance, the difficulty of effective integration of industrial capital and financial capital, and the regulatory system needs to be improved. It is suggested that the management and control technology of the main risks in the integration of industry and finance in the process of new and old kinetic energy conversion should start from five aspects: first, managers should correctly position the combination of production and finance strategies from the value of the enterprise; second, managers should establish a scientific and reasonable corporate governance structure Third, managers should strengthen restrictions on related party transactions within enterprise groups; fourth, management should establish 
necessary firewall systems; fifth, managers should innovate external production and financial supervision systems.

\section{REFERENCES}

[1] Moderneconomicsystem

$[\mathrm{EB} / \mathrm{OL}]$

https://baike.baidu.com/item/\%E7\%8E\%B0\%E4\%BB

$\% \mathrm{~A} 3 \% \mathrm{E} 5 \% 8 \mathrm{C} \% 96 \% \mathrm{E} 7 \% \mathrm{BB} \% 8 \mathrm{~F} \% \mathrm{E} 6 \% \mathrm{~B} 5 \% 8 \mathrm{E} \% \mathrm{E} 4 \%$ $\mathrm{BD} \% 93 \% \mathrm{E} 7 \% \mathrm{~B} 3 \% \mathrm{BB} / 22374143$

[2] Fu Lin. Financial support for the conversion of old and new kinetic energy in manufacturing $[\mathrm{J}]$. China Finance, 2019 (20): 54-56.

[3] Yuan Changqing. Providing insurance guarantee for new and old kinetic energy conversion and industrial upgrading [J]. Enterprise Management, 2019 (10): 45.

[4] Shao Lin. Research on the Financial Support Path of Shandong Province's Manufacturing Industry Transformation and Upgrade under the Conversion of New and Old Kinetic Energy [J]. Journal of Shandong Institute of Business Technology, 2019, 19 (05): 10-12 +25 . 